\title{
Peripheral $\alpha$-Defensins 1 and 2 are Elevated in Alzheimer's Disease
}

\author{
Andrew D. Watt ${ }^{\mathrm{a}, \mathrm{c}}$, Keyla A. Perez ${ }^{\mathrm{a}, \mathrm{c}}$, Ching-Seng Ang ${ }^{\mathrm{d}}$, Paul O’Donnell ${ }^{\mathrm{d}}$, Alan Rembach ${ }^{\mathrm{a}}$, \\ Kelly K. Pertile ${ }^{\mathrm{a}}$, Rebecca L. Rumble ${ }^{\mathrm{a}}$, Brett O. Trounson ${ }^{\mathrm{a}}$, Christopher J. Fowler ${ }^{\mathrm{a}}$, Noel G. Faux ${ }^{\mathrm{a}}$, \\ Colin L. Masters ${ }^{\mathrm{a}}$, Victor L. Villemagne ${ }^{\mathrm{a}, \mathrm{e}}$ and Kevin J. Barnham ${ }^{\mathrm{a}, \mathrm{b}, \mathrm{c}, *}$ \\ ${ }^{\mathrm{a}}$ The Florey Institute of Neuroscience and Mental Health, Bio21 Molecular Science and Biotechnology Institute, \\ The University of Melbourne, Parkville, Melbourne, VIC, Australia \\ ${ }^{\mathrm{b}}$ Department of Pharmacology, Bio21 Molecular Science and Biotechnology Institute, The University of Melbourne, \\ Parkville, Melbourne, VIC, Australia \\ ${ }^{\mathrm{c}}$ The Neuroproteomics Platform, Bio21 Molecular Science and Biotechnology Institute, The University of \\ Melbourne, Parkville, Melbourne, VIC, Australia \\ ${ }^{\mathrm{d}}$ Mass Spectrometry and Proteomics Facility, Bio21 Molecular Science and Biotechnology Institute, The University \\ of Melbourne, Parkville, Melbourne, VIC, Australia \\ ${ }^{\mathrm{e}}$ Department of Nuclear Medicine and Centre for PET, Austin Health, Heidelberg, VIC, Australia
}

Accepted 15 October 2014

\begin{abstract}
Biomarkers enabling the preclinical identification of Alzheimer's disease (AD) remain one of the major unmet challenges in the field. The blood cellular fractions offer a viable alternative to current cerebrospinal fluid and neuroimaging modalities. The current study aimed to replicate our earlier reports of altered binding within the AD-affected blood cellular fraction to copper-loaded immobilized metal affinity capture (IMAC) arrays. IMAC and anti-amyloid- $\beta$ (A $\beta$ ) antibody arrays coupled with mass spectrometry were used to analyze blood samples collected from 218 participants from within the AIBL Study of Aging. Peripheral A $\beta$ was fragile and prone to degradation in the AIBL samples, even when stored at $-80^{\circ} \mathrm{C}$. IMAC analysis of the AIBL samples lead to the isolation and identification of alpha-defensins 1 and 2 at elevated levels in the AD periphery, validating earlier findings. Alpha-defensins 1 and 2 were elevated in AD patients indicating that an inflammatory phenotype is present in the $\mathrm{AD}$ periphery; however, peripheral $\mathrm{A} \beta$ levels are required to supplement their prognostic power.
\end{abstract}

Keywords: $\alpha$-defensins, Alzheimer's disease, amyloid- $\beta$, biomarkers, blood, inflammation, mass spectrometry

\section{INTRODUCTION}

With underlying amyloid- $\beta(A \beta)$ pathology preceding the clinical onset of Alzheimer's disease (AD) by upwards of 20 years [1], it is recognized that to be effective, disease-specific therapeutic interventions should be implemented within the preclinical stages of the

\footnotetext{
*Correspondence to: Kevin Barnham, The Florey Institute of Neuroscience and Mental Health and Department of Pharmacology, The University of Melbourne, VIC, 3010 Australia. Tel.: +61 3 83442555; Fax: +61 3 93476750; E-mail: kbarnham@unimelb.edu.au.
}

disease, before synaptic loss and neuronal degeneration are largely irreversible [2]. However in order to implement such a strategy, peripheral biomarkers allowing preclinical identification of at-risk individuals are needed.

To date, efforts to identify peripheral biomarkers for $\mathrm{AD}$ have focused on plasma $\mathrm{A} \beta$ levels; however, the inherent variability of these investigations (reviewed in [3]) have led investigators to turn their attention toward non-A $\beta$-centric blood-borne biomarkers. Previous investigations have reported that altered levels are present in $\mathrm{AD}$ for a number of non- $\mathrm{A} \beta$ related 
biomarkers including plasma signaling and inflammatory proteins [4] and clusterin [5]. Over the last five years, longitudinal levels of plasma analytes have been monitored in two large-scale studies: The Alzheimer's Disease Neuroimaging Initiative (ADNI) and The Australian Imaging Biomarker and Lifestyle Flagship Study of Aging (AIBL). Using serial annual measurements, the ADNI study reported that a number of pathology analytes, including creatinine, glucose, and cholesterol, may influence plasma $A \beta$ expression [6]. Like ADNI, the AIBL study also focused on the influence of pathology analytes on $A \beta$ levels, finding that inflammatory and renal function analytes were significant covariates [7] and that a panel of such markers were capable of distinguishing $\mathrm{AD}$ patients from controls [8] in addition to predicting neocortical $\mathrm{A} \beta$ burden [9]. Although a degree of overlap was observed between the two studies, there was also a large number of analytes that were unique to each cohort, highlighting the need to account for variations in sample processing [3] as well as other comorbidities, particularly those often associated with age.

While requiring further validation, these investigations highlight the potential of non- $\mathrm{A} \beta$-centric biomarkers in the diagnosis of AD. However, they also highlight the proclivity for researchers to focus on plasma biomarkers at the expense of biomarkers in other blood fractions, despite a number of reports that $A \beta$ is readily observable within the cellular blood fractions [10-12]. In 2010, using a technique previously used to identify potential biomarkers in cerebrospinal fluid (CSF) [13, 14], namely immobilized metal affinity capture (IMAC) in conjunction with SELDI-TOF MS [15], we identified three candidate biomarkers in the AD-affected blood cellular fraction [15]. These candidate markers were significantly correlated with clinical measures of disease, including Mini-Mental State Examination (MMSE), composite memory, brain $\mathrm{A} \beta$ burden, and hippocampal volume. Most pertinently, however, was the finding that a regression model combining levels of these candidate markers with peripheral $A \beta$ levels [10] enabled the distinction of AD patients from healthy controls (HC) with high specificity (90\%) and sensitivity $(77 \%)$ and, furthermore, enabled the separation of individuals with mild cognitive impairment (MCI) who progressed to $\mathrm{AD}$ from those MCI that did not [15].

The present investigation aimed to replicate our earlier findings [15] using samples obtained from the AIBL. Blood cellular fraction samples were analyzed using copper-loaded IMAC in conjunction with SELDI-TOF MS.

\section{MATERIALS AND METHODS}

An outline of the materials and methodologies utilized in the current study, detailed methodologies are provided in the supplementary materials.

\section{Human samples}

Blood samples were collected from 218 participants in the AIBL study, 72 elderly subjects clinically diagnosed with mild to moderate $\mathrm{AD}, 113$ age-matched cognitively unimpaired individuals, and 33 individuals classified as presenting with MCI [16]. Samples were collected at two time points: Baseline and 18-month follow-up.

Neuropsychological and neuroimaging assessments

All participants underwent a number of neuropsychological assessments which have previously been described [16] and a small subset of participants $\left(\mathrm{n}_{\mathrm{HC}}=18, \mathrm{n}_{\mathrm{MCI}}=13, \mathrm{n}_{\mathrm{AD}}=9\right)$ also underwent $\mathrm{A} \beta$ imaging with $\left[{ }^{11} \mathrm{C}\right] \mathrm{PiB}$ PET as previously described [17].

\section{Preparation of human samples}

Venesection was used to collect $4 \mathrm{~mL}$ samples of whole blood in EDTA vacutainers $1.6 \mathrm{mg} / \mathrm{mL}$ (CEDTA, Greiner Bio-One) following overnight fasting. Blood processing commenced between 60 and $240 \mathrm{~min}$ of sample acquisition. Blood was separated into plasma, cellular fraction, red blood cells (RBC) and white blood cell (WBC) fractions. All samples were stored at $-80^{\circ} \mathrm{C}$ until required, thus ensuring that all samples only underwent a single freeze/thaw cycle. Full blood processing details are provided in the supplementary materials.

\section{SELDI-TOF MS analysis}

Mass spectrometric analysis of the blood cellular fractions were carried out using either ProteinChip ${ }^{\circledR}$ PS10 Arrays (Bio-Rad; CAT \#C55-30044) loaded with WO2 $(2 \mu \mathrm{L}$ at $0.25 \mathrm{mg} / \mathrm{mL})$ or ProteinChip ${ }^{\circledR}$ IMAC30 Arrays (Bio-Rad; CAT \# C57-30078) charged with $\mathrm{CuSO}_{4}(100 \mu \mathrm{L}$ at $0.1 \mathrm{M}$; Chem-Supply; Gillman, South Australia).

All samples were analyzed blinded to diagnostic status, using a ProteinChip SELDI System Enterprise Edition (BioRad). Full methodological details of this 
analysis including replicate analysis are provided in the supplementary text.

\section{Isolation and purification of candidate markers}

Candidate markers were isolated in solution using ProteinChip IMAC Spin Columns (Bio-Rad; CAT \# C54-00027) loaded with $0.1 \mathrm{M} \mathrm{CuSO}_{4}$. Eluted material was pooled and then frozen at $-80^{\circ} \mathrm{C}$ before undergoing overnight lyophilization. Full details are provided in the supplementary materials.

Lyophilized samples were resuspended and analyzed using an analytical Shimadzu system coupled with an analytical C5 Jupiter Phenomenex Column (300 A). Subsequent to HPLC, matrix-assisted laser desorption/ionization (MALDI)-TOF MS was used to assess the fractions of interest.

\section{Identification of candidate markers}

Samples underwent tryptic digestion before undergoing analysis by liquid chromatography-mass spectrometry (LC-MS) using a LTQ Orbitrap Elite (Thermo Scientific) with a nanoelectrospray interface coupled to an Ultimate 3000 RSLC nanosystem (Dionex).

\section{Statistical analysis}

Continuous variables including peak intensities and measures of disease severity were tested for normality using the Shapiro-Wilk test. $P$-values were corrected for multiple testing controlling the false discovery rate [18]. Partial Least squares (PLS) regression was performed to generate predictive models using a combination of peak intensities from the three candidate markers and other clinical variables in accordance to our previous study [15]. Data are presented as mean \pm standard deviation (SD) unless otherwise stated. All analyses were undertaken using Graphpad Prism $^{\circledR}$ for Windows (Version 5.03, 2009), XLSTAT (Version 2010.5.05) and R (Version 2.9.2. The R Foundation for Statistical Computing. (2009)).

\section{RESULTS}

\section{Participant demographics}

Demographic, neuropsychological and neuroimaging information pertaining to the 218 AIBL participants are outlined in Supplementary Table 1.
Blood-borne A $\beta$ was not reliably observed in the AIBL samples

Cursory examination of the resulting WO2 spectra confirmed the inherent variability of the samples outlined in the CV data (Supplementary Table 2); however, it also revealed an almost complete absence of detectable $A \beta$ within the AIBL samples (Fig. 1). The absence of detectable $A \beta$ was a remarkable finding as, not only did it contradict our earlier findings [10], it contradicted the preparatory stages of the current investigation where abundant levels of both monomeric and dimeric $A \beta$ were observed. Further investigation established that while $A \beta$ levels were readily observable in the month following sample collection, analysis of the same samples that were stored at $-80^{\circ} \mathrm{C}$ for $\sim 12$ months revealed that $A \beta$ in the samples was no longer present at detectable levels (Supplementary Figure 1). These observations were inconsistent with our experiences working with cellular fraction samples from the Healthy Aging Study, where A $\beta$ levels were observed at stable levels over multiple years, and led us to question whether differences in the pre-analytical aspects of the studies had inadvertently influenced the stability of $\mathrm{A} \beta$ in the samples.

Comparisons between the pre-analytical protocols of AIBL and the Healthy Aging Study

Comparisons between the pre-analytical protocols of AIBL and the Healthy Aging Study revealed consensus between the two studies with regard to anti-coagulant, tube type, centrifugation parameters and storage times. However, there were discrepancies between the two studies regarding the time taken to process the samples (Supplementary Table 3).

\section{Identifying potential biomarkers using immobilized metal affinity capture}

Three robust peaks were identified which were able to significantly differentiate between AD patients and controls, following adjustments for multiple testing (Supplementary Table 4). The candidate markers $3370 \mathrm{Da}$ and $3440 \mathrm{Da}$, were consistent with those observed in our previous study [15] and were both elevated in the $\mathrm{AD}$ cellular fraction compared to control. The candidate biomarker at $5352 \mathrm{Da}$ was observed at decreased levels in AD compared to control. The three markers will henceforth be referred to as candidate markers (CM) CM3370, CM3440, and CM5352 respectively (Fig. 2). Ratios between 
a

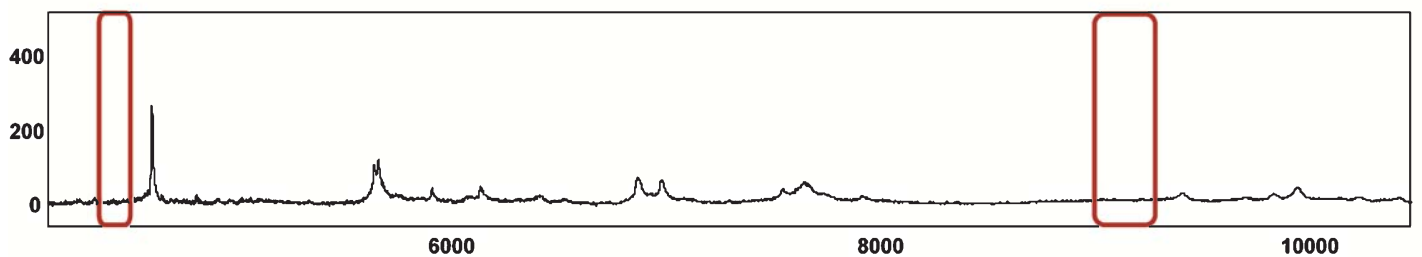

b

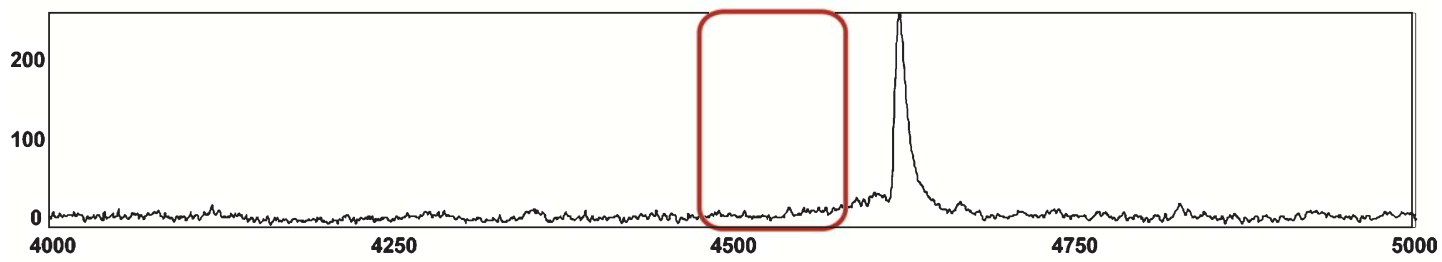

C

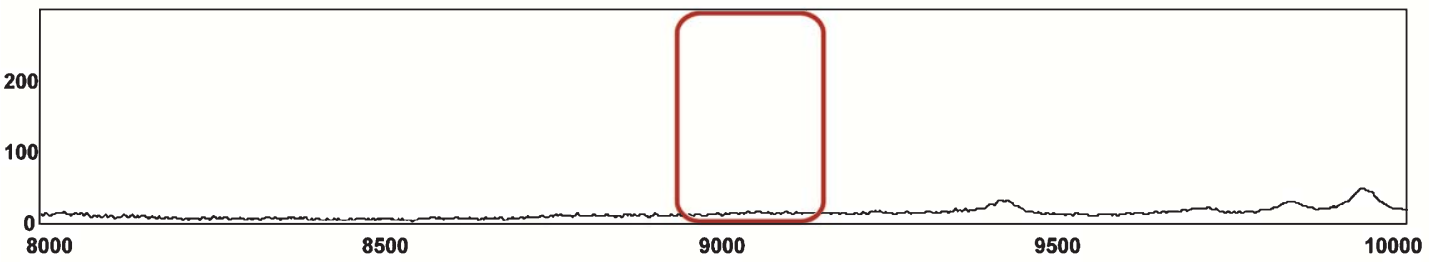

d

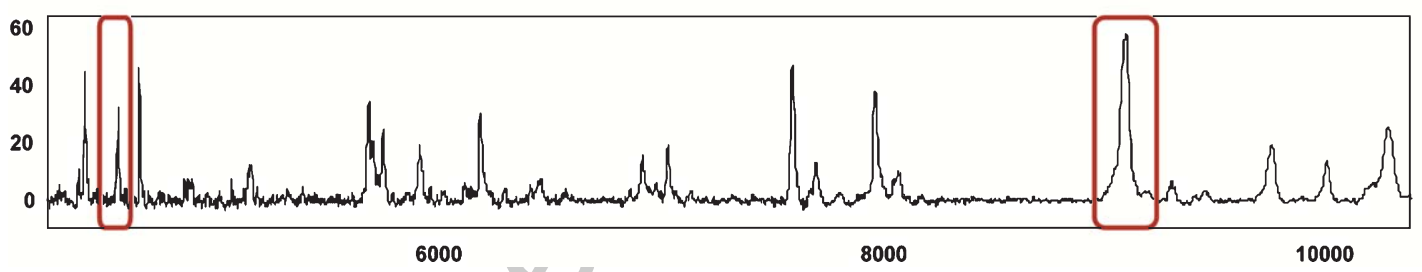

Fig. 1. Representative $A \beta$ profiles of the AIBL cellular fraction samples. (a) Representative WO2 SELDI-TOF MS spectra of the AD-affected blood cellular fraction showing the lack of both monomeric (b) and dimeric (c) A $\beta$ present in the AIBL samples. (d) Representative WO2 SELDI-TOF MS spectra of the AD-affected blood cellular fraction from the earlier Healthy Aging Study [10], showing both monomeric and dimeric $A \beta$. Note that this analysis was conducted using a Ciphergen PBS IIC.

CM3370/CM5352 ( $p=0.0001)$ and CM3440/CM5352 $(p=0.0005)$ resulted in significant differences between $\mathrm{AD}$ patients and $\mathrm{HC}$, but no significant differences were observed between either $\mathrm{AD}$ patients or $\mathrm{HC}$ and MCI participants (Supplementary Figure 2). No significant differences were observed across the groups for CM3370/CM3440 $(p=0.2)$.

\section{Effect of APOE genotype on candidate biomarkers} levels

Peak intensities of CM5352 were significantly higher in apolipoprotein E (APOE) $\varepsilon 4$ non-carriers compared to $\varepsilon 4$ heterozygotes ( $p=0.002$ ), but not compared to $\varepsilon 4$ homozygotes (Supplementary Figure 3).
No significant differences were observed across the groups for CM3370 or CM3440.

Correlations between candidate biomarkers and measures of disease severity

Correlations between the peak intensities of the candidate biomarkers and clinical measures of disease severity were conducted to ascertain the level of overlap between $\mathrm{AD}$ progression and the underlying pathological processes in the blood (Table 1). These comparisons revealed that both CM3370 and CM3440 were significantly associated with the three measures of disease severity: MMSE (CM3370 $\mathrm{r}_{\mathrm{S}}=-0.239$, $p<0.001$; CM3440 $\left.\mathrm{r}_{\mathrm{S}}=-0.203, p<0.01\right)$, Clinical 
a

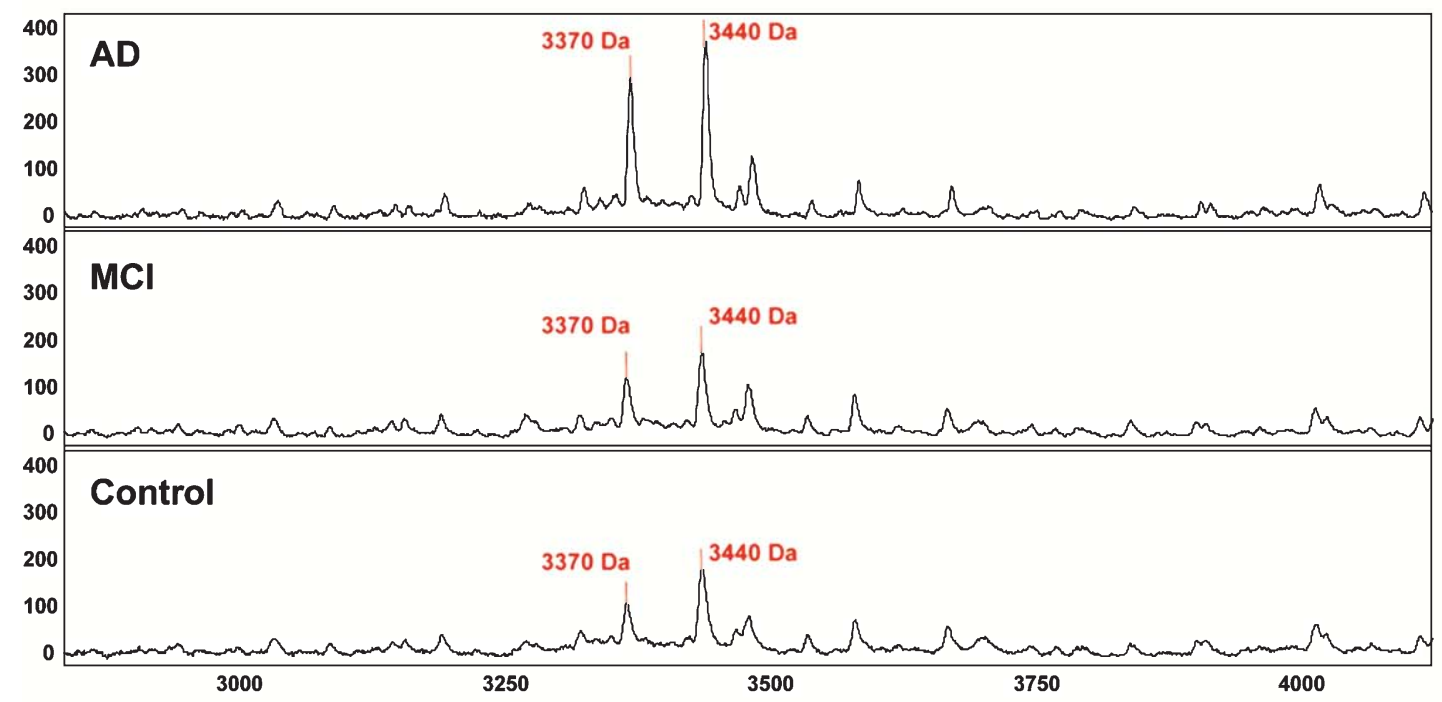

b

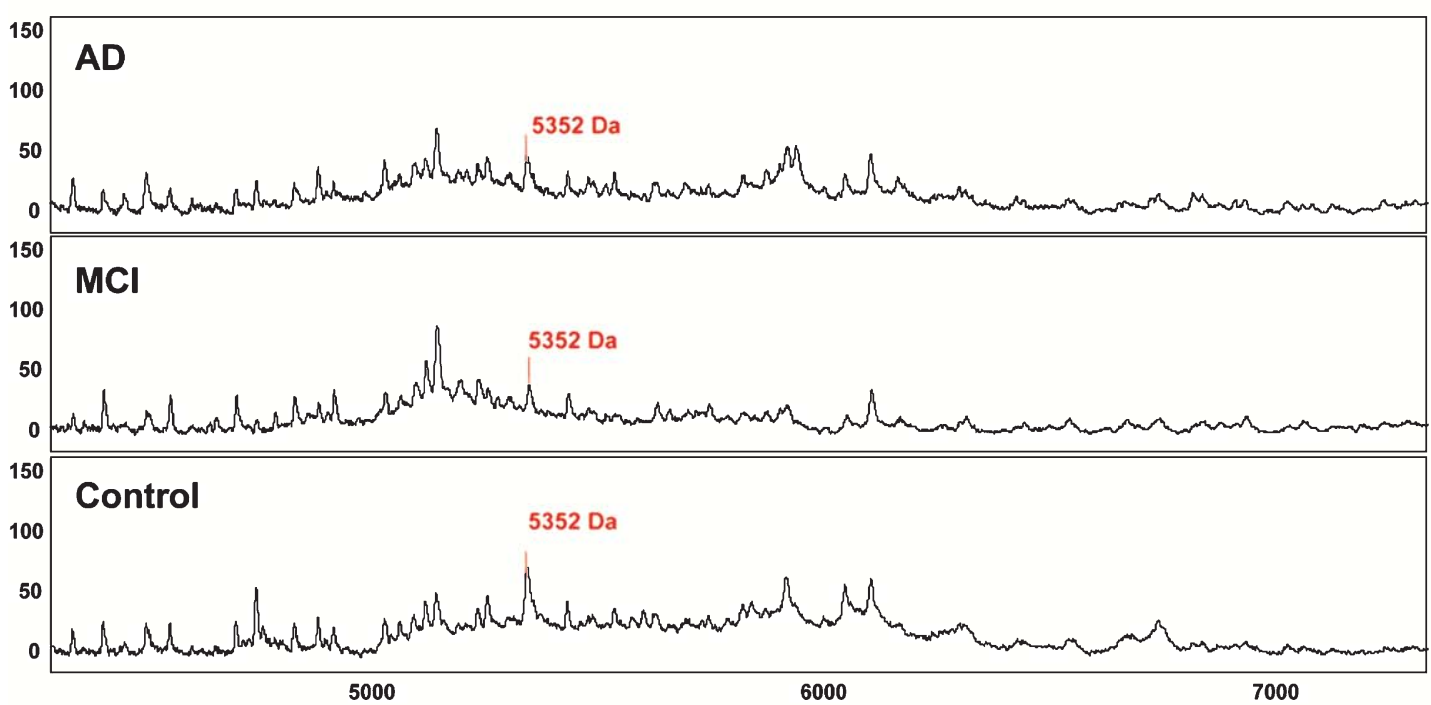

C

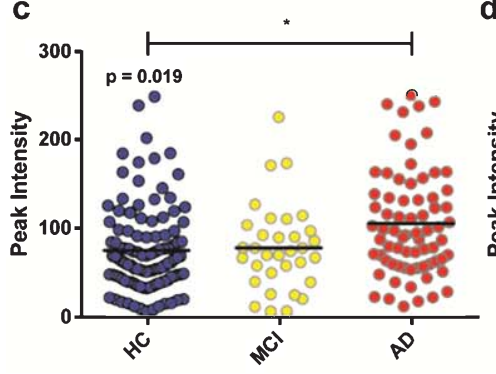

d

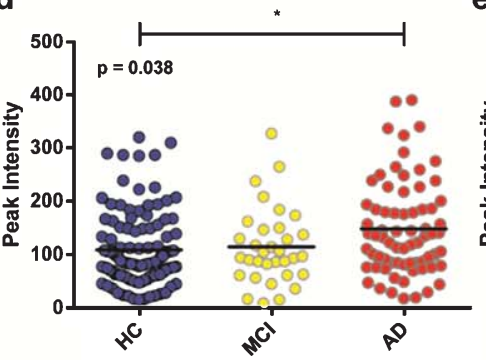

e

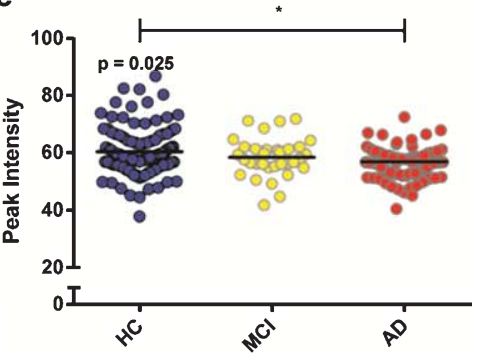

Fig. 2. Representative SELDI-TOF MS spectra arising from the copper-loaded IMAC analysis of AIBL blood cellular fraction samples. (a) Spectra illustrate elevated levels of candidate markers $3370 \mathrm{Da}$ and $3440 \mathrm{Da}$ in AD blood compared to control and (b) decreased levels of candidate marker $5352 \mathrm{Da}$. Scatterplots for candidate markers (c) $3370 \mathrm{Da}(p=0.019)$, (d) $3440 \mathrm{Da}(p=0.038)$, and (e) $5352 \mathrm{Da}(p=0.025)$, respectively. 
Table 1

Correlations between candidate biomarkers and clinical measures of disease. Spearman's correlation coefficients between candidate biomarker peak intensities, candidate marker ratios and clinical measures of $\mathrm{AD}$ as assessed by neuropsychological examination and neuroimaging

\begin{tabular}{|c|c|c|c|c|c|}
\hline & CM3370 & CM3440 & CM5352 & CM3370/CM5352 & CM3440/CM5352 \\
\hline Age & 0.104 & 0.078 & -0.011 & 0.096 & 0.073 \\
\hline Mini-Mental State Exam & $-0.238 * * *$ & $-0.203 * *$ & $0.171 *$ & $-0.253 * * *$ & $-0.225 * * *$ \\
\hline \multicolumn{6}{|l|}{ Clinical Dementia Rating } \\
\hline Score & $0.171 *$ & $0.144 *$ & $-0.175^{*}$ & $0.199 * *$ & $0.177 * *$ \\
\hline Sum of boxes & $0.196 * *$ & $0.164 *$ & $-0.226 * * *$ & $0.233 * * *$ & $0.208 * *$ \\
\hline \multicolumn{6}{|c|}{ Hospital Anxiety and Depression Scale } \\
\hline Depression & 0.044 & 0.020 & -0.125 & 0.065 & 0.037 \\
\hline Anxiety & -0.011 & -0.003 & -0.119 & 0.009 & 0.013 \\
\hline Neocortical PiB SUVR † & 0.257 & 0.194 & $-0.448 * *$ & 0.271 & $0.302 * *$ \\
\hline
\end{tabular}

tides in the sample (Fig. 3a). CM5352 on the other hand, appeared to be predominantly located within the RBC fraction (Fig. 3b); however, the relative intensity of the peak and the presence of neighboring peptides made further purification of this candidate marker difficult.

Purification and identification of CM3370 and CM3440 from WBCs

CM3370 and CM3440 were isolated and purified using ProteinChip IMAC Spin Columns in conjunction with HPLC (Fig. 3c-d). A trypsin digest of the HPLC fraction was followed by LC MS/MS in an effort to identify the resulting tryptic peptides (Supplementary Table 5). This analysis identified three tryptic peptides belonging to $\alpha$-Defensin- 1 , also known as human neutrophil peptide-1 (HNP-1) and enabled near full sequence coverage of the peptide (Supplementary Figure 5). These findings enabled the unambiguous assignment of peak $3440 \mathrm{Da}$ observed in the IMAC analysis as HNP-1. Furthermore, the identical HPLC retention times of CM3440 and CM3370 was considered sufficient evidence to assign the 3370 Da IMAC peak as HNP-2. The sequence of HNP-2 is identical to HNP-1 with the exception of a single N-terminal alanine which is missing from the truncated HNP-2.

Confirmatory analysis was performed using electrospray ionization (ESI) fragmentation coupled with high accuracy measurements. HPLC purified fractions of CM3440 were compared to synthetic HNP-1 on a nanoscale HPLC coupled to an Orbitrap Elite MS, with both fractions showing matching retention times and mass (Fig. 4). Mass alignment between CM3440 and synthetic HNP-1 showed differences of less than $3.4 \mathrm{ppm}$ for the $[\mathrm{M}+4 \mathrm{H}]^{4+}$ peptide and less than $1.7 \mathrm{ppm}$ for the $[\mathrm{M}+5 \mathrm{H}]^{5+}$ peptide. Further isotopic modelling using the mMass software on the $[\mathrm{M}+5 \mathrm{H}]^{5+}$ were enriched within the $\mathrm{WBC}$ fraction in AD patients, observed as clean peaks unimpeded by adjacent pep- 


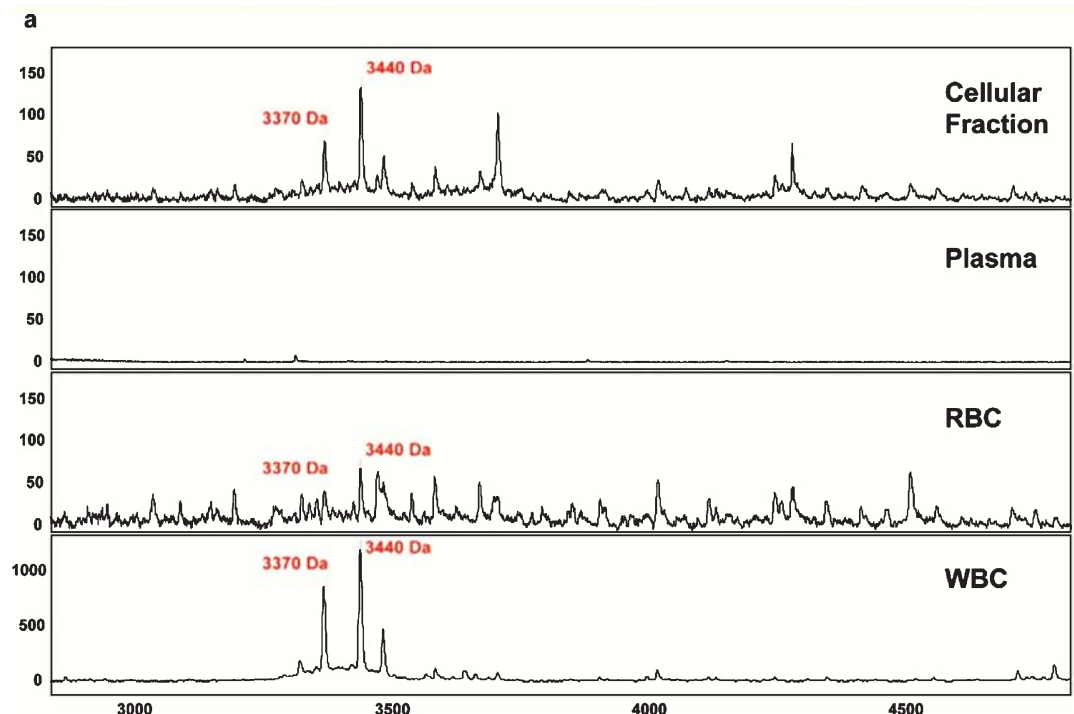

b
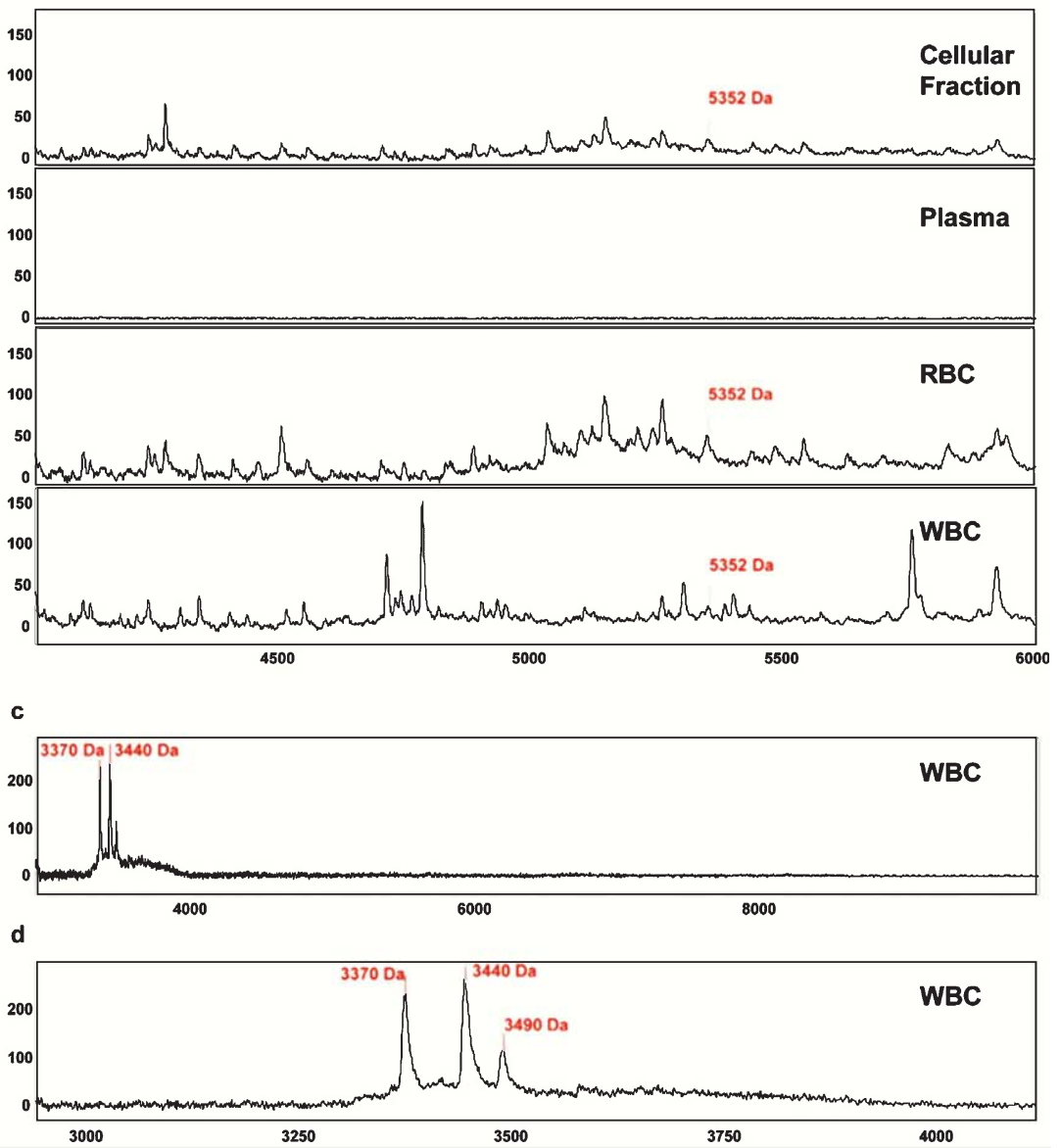

Fig. 3. Isolation and purification of candidate biomarkers from AIBL blood fractions. (a) Representative SELDI-TOF MS spectra arising from copper-loaded IMAC analysis of the cellular fraction (top), plasma (second), red blood cell (RBC; third), and white blood cell (WBC; bottom) fractions of AD-affected blood, indicates that CM3370 and CM3440 are enriched within WBCs. (b) CM5352 appears to be predominantly found within the RBC fraction. Pooled WBCs were isolated using copper-loaded IMAC spin column analysis followed by HPLC purification. (c) Full MALDI-TOF MS spectra and d zoomed spectra. 


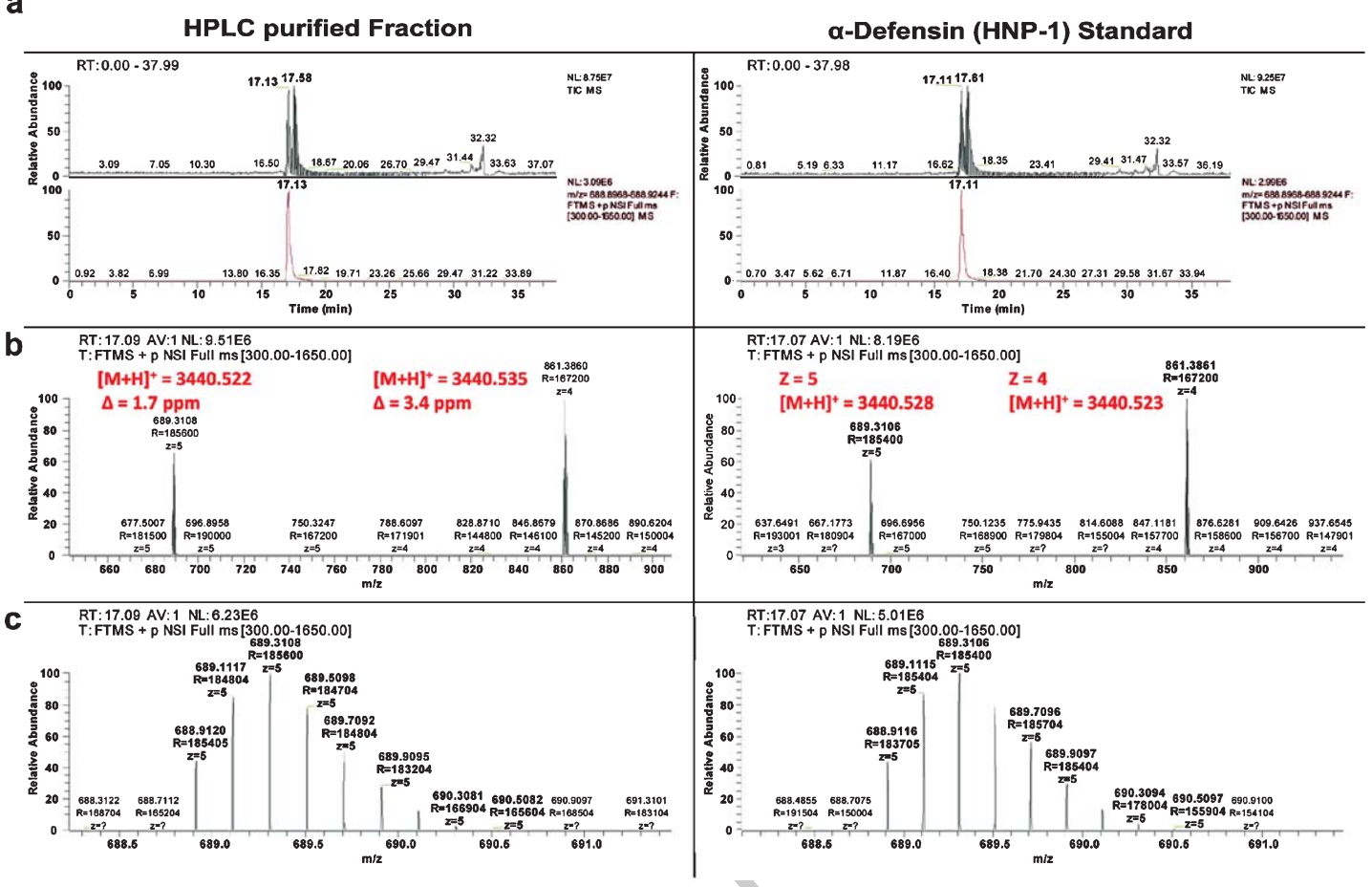

Fig. 4. Identification of CM3440 as human neutrophil peptide-1. Comparative analysis of HPLC purified CM3440 against synthetic human neutrophil peptide (HNP)-1 enabled the identification of CM3440 as HNP-1. (a) Total ion chromatogram (top panel) and extracted ion chromatogram (lower panel) of the $[\mathrm{M}+5 \mathrm{H}]^{+}$peptide indicates that both samples display near identical HPLC retention time (lower panel). (b) MS spectra of the $[\mathrm{M}+5 \mathrm{H}]^{5+}$ and $[\mathrm{M}+4 \mathrm{H}]^{4+}$ peptide showing differences of less than $3.4 \mathrm{ppm}$ for the $\mathrm{H}^{4+}$ peptide and less than $1.7 \mathrm{ppm}$ for the $\mathrm{H}^{5+}$ peptide. (c) Enhanced zoom of the $[\mathrm{M}+5 \mathrm{H}]^{5+}$ spectra demonstrates that isotopic clustering of the two fractions resulted in similar masses between both samples. $\mathrm{Z}=$ charge state and $\mathrm{R}=$ resolution.

peptide enabled precise match to both the theoretical and synthetic peptide's isotopic patterns.

\section{Alpha-defensins and white blood cell fractions}

The identification of HNP-2 and HNP-1 raised the question of whether the elevation of these biomarkers in the periphery of $\mathrm{AD}$ patients was an indication of aberrant WBC levels. Spearman's correlation was used to analyze the association between HNP levels and levels of WBCs, neutrophils and lymphocytes (Fig. 5). These analyses revealed strong positive correlations between $\alpha$-defensin levels and both white cell count (HNP-2 $\mathrm{r}_{\mathrm{S}}=0.377, p<0.0001 ; \mathrm{HNP}-1$ $\left.\mathrm{r}_{\mathrm{S}}=0.354, p<0.0001\right)$ and neutrophil count reference interval (HNP-2 $\mathrm{r}_{\mathrm{S}}=0.426, p<0.0001$; HNP-1 $\left.\mathrm{r}_{\mathrm{S}}=0.402, p<0.0001\right)$. However, no correlation was observed between $\alpha$-defensin levels and lymphocyte count reference intervals (HNP-2 $\mathrm{r}_{\mathrm{S}}=0.053, p>0.05$; HNP-1 $\left.\mathrm{r}_{\mathrm{S}}=0.044, p>0.05\right)$. Further analysis revealed that $\alpha$-defensin levels remained elevated in AD- affected blood following normalization to neutrophil levels (HNP-2 $p=0.008$, HNP-1 $p=0.032$; Fig. 5).

\section{Using Partial Least Squares regression to generate predictive models}

In order to enhance the distinction between the spectral profiles of $\mathrm{AD}$ patients and their healthy counterparts, PLS regression was utilized to investigate which combination of the candidate peaks, if any, would allow for the optimal separation of the clinical diagnoses. In accordance with our earlier investigation [15], data for these models included peak intensities of the candidate peaks, ratios between candidate markers and participants' age, gender and APOE status. However, only participant's age and APOE $\varepsilon 4$ were found to have variable importance of the projection (VIP) values 1 standard deviation above 0.8 (Supplementary Table 6). These findings indicated that the candidate markers were not able to produce a robust diagnostic model and thus no subsequent PLS analyses were 
a

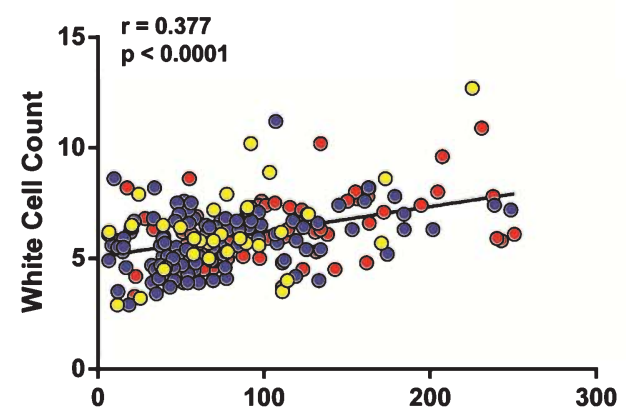

C

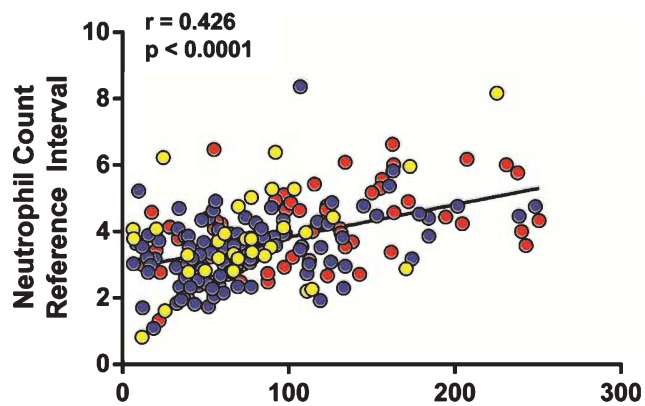

e

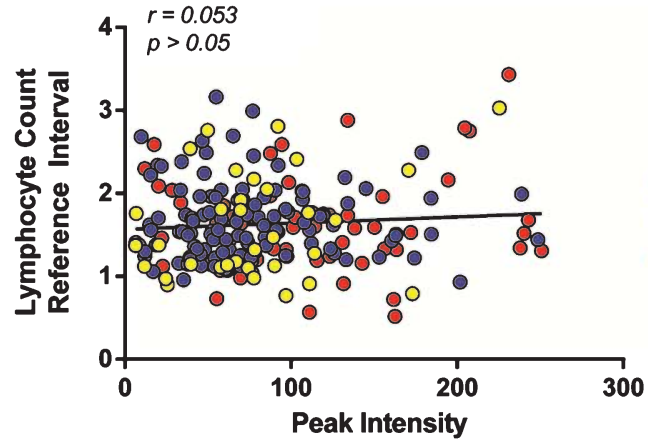

g

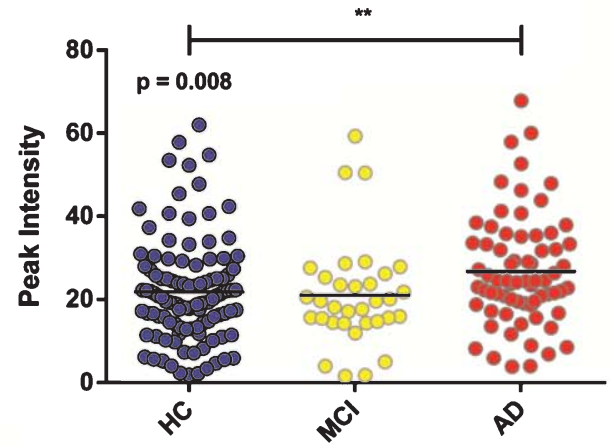

b

HNP-1

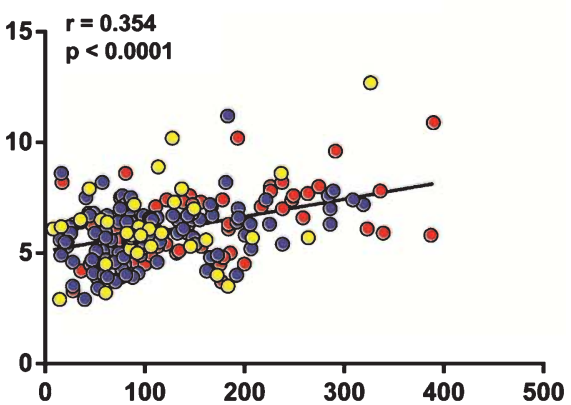

d

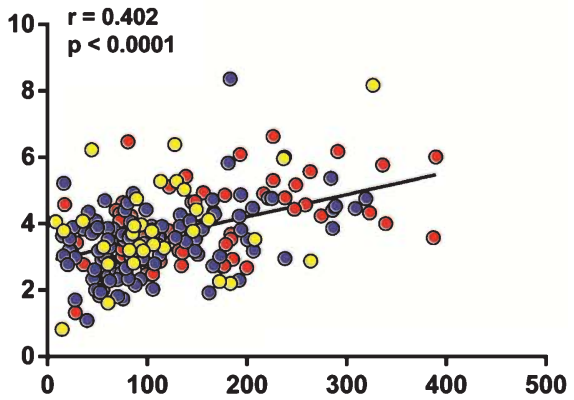

f

MC

$\mathrm{HC}$

$A D$

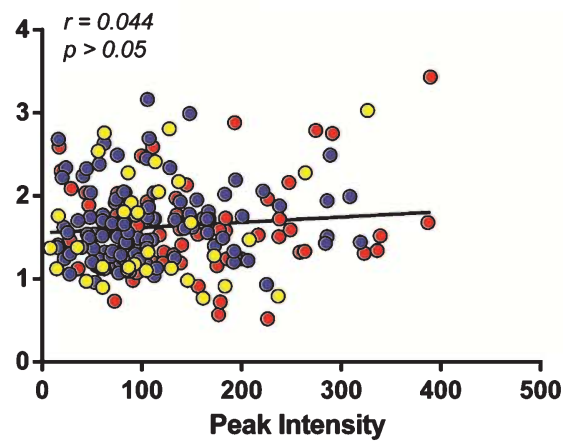

h

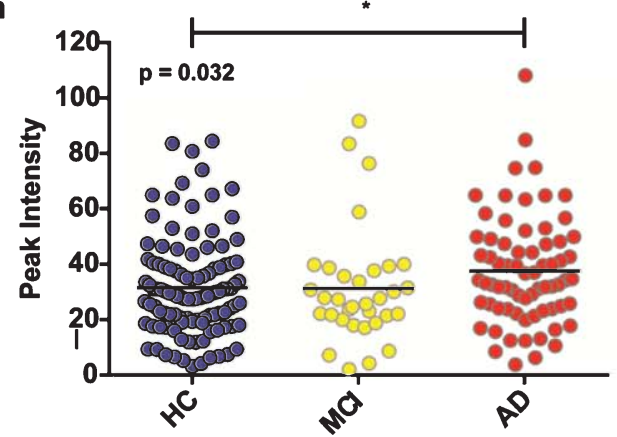

Fig. 5. Correlations between candidate biomarkers and WBC components and comparative analyses of $\alpha$-defensin levels normalized to neutrophil levels. a-f) Spearman's correlations revealed strong positive correlations between $\alpha$-defensin levels and both white cell count $\left(\mathrm{HNP}-2 \mathrm{r}_{\mathrm{S}}=0.377\right.$, $\left.p<0.0001 ; \mathrm{HNP}-1 \mathrm{r}_{\mathrm{S}}=0.354, p<0.0001\right)$ and neutrophil count reference interval (HNP-2 $\left.\mathrm{r}_{\mathrm{S}}=0.426, p<0.0001 ; \mathrm{HNP}-1 \mathrm{r}_{\mathrm{S}}=0.402, p<0.0001\right)$. No correlation was observed between $\alpha$-defensin levels and lymphocyte count reference intervals. Comparative analyses demonstrated that following normalization to neutrophil levels, $\alpha$-defensin levels, both (g) HNP-2 and (h) HNP-1 remained significantly elevated in AD-affected blood ( $p=0.008$ and $p=0.032$, respectively). 
performed. It should be noted that the success of HNP2 (CM3370) and HNP-1 (CM3440) in earlier PLS models was reliant on monomeric and dimeric $A \beta$ levels [15]; however, the instability of $A \beta$ levels in the AIBL samples rendered current attempts to produce predictive models ineffective. Attempts to generate predictive models using HNP levels in association with previously reported plasma A $\beta$ levels [19]; however, these values were not able to add to the predictive power of the model (data not shown).

An additional attempt to generate a predictive PLS model was undertaken by combining $\alpha$-defensin levels with the panel of 18 biomarkers identified in the AIBL cohort by Doecke et al. [8]. This analysis indicated that participant's age, APOE $\varepsilon 4$, insulin-like growth factor binding protein 2, pancreatic polypeptide and interleukin 17 had VIP values 1 standard deviation above 0.8 (Supplementary Table 7) and indicated that levels of the $\alpha$-defensins and CM5352, in addition to ratios between these marker levels, as measured by IMAC, were not able to provide additional predictive power to the model produced by Doecke et al. [8].

\section{DISCUSSION}

The identification of a panel of biomarkers capable of identifying preclinical AD remains one of the major unmet goals in the field. The measurement of cortical $A \beta$ burden using PiB-PET and CSF measurements of $A \beta$ and tau remain the most clinically effective diagnostic markers of AD [20-22], with both showing strong potential as measures of preclinical disease $[1,23]$. However, given the goal of screening asymptomatic individuals, PET imaging and CSF sampling remain logistically and economically impractical [21, 24]. Such obstacles could be overcome by utilizing a more readily accessible biological sample, such as blood. As in previous studies [10,15], the fractionation protocol utilized in the current investigation was kept purposely minimalistic; reflective of the standard protocols utilized in clinical laboratories worldwide. The plasma and cellular fractions were separated before the cellular fraction was analyzed using IMAC in conjunction with SELDI-TOF MS, leading to the identification of three candidate biomarkers of AD: HNP-1, HNP-2 and CM5352.

CM5352 levels were lower in the AD cellular fraction and were significantly associated with cognitive performance and cortical amyloid burden. Unfortunately, the low levels of CM5352 observed in the cellular fraction combined with the abundance of neighboring peaks prevented further identification of this marker. This highlights a limitation of the combined use of IMAC and SELDI-TOF MS in that the peptide or protein of interest may not be suitable for identification due to low peak intensity/poor relative abundance or the presence of extraneous peaks in a similar mass range. Such peaks are often not resolvable using electrophoresis and subsequent MS/MS identification.

The observation of elevated levels of HNP-1 and HNP-2 in the AD cellular fraction was of particular importance as it corroborated our earlier findings in an independent cohort [15]. As in the earlier study, these were observed to be elevated in $\mathrm{AD}$ patients through processes independent of age, gender and APOE status; indicating that the elevation of these blood markers was likely driven by underlying pathogenic processes.

Defensins are a family of mammalian peptides found in a number of human biological fluids including blood, milk, saliva, tears, and urine [25-27]. Three $\alpha$-defensins, HNP-1, HNP-2, and HNP-3, are cationic antimicrobial peptides that are produced predominantly by human neutrophils and are active components of the innate immune system [26, 28-30]. The sequence of the three peptides is identical with the exception of a single $\mathrm{N}$-terminal residue, which is an alanine in HNP-1, an aspartate in HNP-3 and which is missing from the truncated HNP-2 [31]. $\alpha$-defensins are released in biological fluids during inflammation [26] and elevated levels of the peptides have previously been reported as markers of cancer [32-34], schizophrenia [35], HIV [36], and herpes simplex virus [37].

The role of inflammation in AD remains somewhat controversial, with researchers continuing to question whether microglial activation in the AD brain has a neuroprotective or neurodegenerative function [38]. However, regardless of their exact role in AD progression, neuropathological and neuroimaging studies have consistently reported that microglial activation accompanies $\mathrm{A} \beta$ deposition in $\mathrm{AD}$ and genes encoding inflammatory proteins are often upregulated in $\mathrm{AD}$, even at the early stages of the disease [39-43]. Reports of elevated inflammatory markers in the AD periphery have also been well established [8, 44-46], leading to speculation regarding the presence of an inflammatory endophenotype in the lead up to a dementia diagnosis $[44,47,48]$. The findings of elevated $\alpha$-defensins provide further support for this notion and indicate that a more thorough understanding of systemic inflammation may help to elucidate the preclinical stages of $\mathrm{AD}$ pathogenesis. 
Our previous investigation indicated that it was the combination of blood borne $A \beta$ and HNP levels that provided the most robust predictive model, while on their own the respective marker lacked the predictive power to be of significant prognostic value [15]. In the present study, it is thought that the extended sample processing time in the AIBL study resulted in decreased sample durability and a consequential lack of data pertaining to levels of monomeric and dimeric $A \beta$. As a result of this, attempts to generate predictive models using levels of HNP-1 and HNP-2 alone were unsuccessful, with all markers failing to meet the requisite VIP levels for inclusion in the model. It is important to note however, that the failure of HNP-1 and HNP-2 to meet the requisite VIP levels for model inclusion is based on the measurement of their levels using broad-based IMAC analysis, rather than a more targeted antibody-based approach; something to be considered in future investigations. However, regardless of the analytical techniques employed to investigate markers of peripheral inflammation, such as the $\alpha$-defensins, the ubiquitous elevation of such markers across a wide range of disease states (cancer [32-34], schizophrenia [35], HIV [36], and herpes simplex virus [37]) necessitates the parallel observation of aberrations in $\mathrm{A} \beta$, tau, or other $\mathrm{AD}$-specific protein levels. Attempts to measure $A \beta$ in these samples were undertaken, albeit unsuccessfully, in the current study; however, peripheral tau levels were not assessed and data pertaining to these levels was not available from the AIBL database.

The deteriorating $A \beta$ signal observed in the AIBL samples over time is of considerable concern and raises the question of whether biofluid samples held within the AIBL, and potentially the ADNI and DIAN, biobanks will contain viable levels of the peptide in the years to come. This finding, whilst requiring further investigation, is testament to the fragile nature of the $\mathrm{A} \beta$ peptide and highlights the logistical difficulties of analyzing longitudinal $A \beta$ levels in complex samples. Finally, despite the aforementioned issues with sample durability, both HNP-1 and HNP-2 remained at significantly elevated levels in the AD periphery; suggesting that these markers offer a more robust measure of disease state than the more fragile $A \beta$ peptides.

The finding that $\alpha$-defensins are elevated in the AD-affected periphery reaffirms, not only our earlier investigation [15], but also the notion that the identification of peripheral inflammation may be a key step toward identifying $\mathrm{AD}$ in its earlier stages. While it is not being asserted that additional investigation into the underlying causes of elevated $\alpha$-defensin levels will further our understanding of $\mathrm{AD}$ pathogenesis; it is clear that non-amyloidogenic biomarkers offer an alternative pathway in the diagnosis and monitoring of AD.

\section{DISCLOSURE STATEMENT}

Authors' disclosures available online (http://www.jalz.com/disclosures/view.php?id=2600).

\section{SUPPLEMENTARY MATERIAL}

The supplementary material is available in the electronic version of this article: http://dx.doi.org/ 10.3233/JAD-142286.

\section{REFERENCES}

[1] Villemagne VL, Burnham S, Bourgeat P, Brown B, Ellis KA, Salvado O, Szoeke C, Macaulay SL, Martins R, Maruff P, Ames D, Rowe CC, Masters CL (2013) Amyloid $\beta$ deposition, neurodegeneration, and cognitive decline in sporadic Alzheimer's disease: A prospective cohort study. Lancet Neurol 12, 357-367.

[2] Sperling RA, Aisen PS, Beckett LA, Bennett DA, Craft S, Fagan AM, Iwatsubo T, Jack CR, Kaye J, Montine TJ, Park DC, Reiman EM, Rowe CC, Siemers E, Stern Y, Yaffe K, Carrillo MC, Thies B, Morrison-Bogorad M, Wagster MV, Phelps CH (2011) Toward defining the preclinical stages of Alzheimer's disease: Recommendations from the National Institute on Aging-Alzheimer's Association workgroups on diagnostic guidelines for Alzheimer's disease. Alzheimers Dement 7, 280-292.

[3] Watt AD, Perez KA, Rembach AR, Masters CL, Villemagne VL, Barnham KJ (2012) Variability in blood-based amyloidbeta assays: The need for consensus on pre-analytical processing. J Alzheimers Dis 30, 323-336.

[4] Ray S, Britschgi M, Herbert C, Takeda-Uchimura Y, Boxer A, Blennow K, Friedman LF, Galasko DR, Jutel M, Karydas A, Kaye JA, Leszek J, Miller BL, Minthon L, Quinn JF, Rabinovici GD, Robinson WH, Sabbagh MN, So YT, Sparks DL, Tabaton M, Tinklenberg J, Yesavage JA, Tibshirani R, Wyss-Coray T (2007) Classification and prediction of clinical Alzheimer's diagnosis based on plasma signaling proteins. Nat Med 13, 1359-1362.

[5] Thambisetty M, Simmons A, Velayudhan L, Hye A, Campbell J, Zhang Y, Wahlund LO, Westman E, Kinsey A, Guntert A, Proitsi P, Powell J, Causevic M, Killick R, Lunnon K, Lynham S, Broadstock M, Choudhry F, Howlett DR, Williams RJ, Sharp SI, Mitchelmore C, Tunnard C, Leung R, Foy C, O'Brien D, Breen G, Furney SJ, Ward M, Kloszewska I, Mecocci P, Soininen H, Tsolaki M, Vellas B, Hodges A, Murphy DG, Parkins S, Richardson JC, Resnick SM, Ferrucci L, Wong DF, Zhou Y, Muehlboeck S, Evans A, Francis PT, Spenger C, Lovestone S (2010) Association of plasma clusterin concentration with severity, pathology, and progression in Alzheimer disease. Arch Gen Psychiatry 67, 739-748.

[6] Toledo JB, Vanderstichele H, Figurski M, Aisen PS, Petersen RC, Weiner MW, Jack CR, Jr., Jagust W, Decarli C, Toga AW, Toledo E, Xie SX, Lee VM, Trojanowski JQ, Shaw LM 
(2011) Factors affecting Abeta plasma levels and their utility as biomarkers in ADNI. Acta Neuropathol 122, 401-413.

[7] Rembach A, Faux NG, Watt AD, Pertile KK, Rumble RL, Trounson BO, Fowler CJ, Roberts BR, Perez KA, Li Q-X, Laws SM, Taddei K, Rainey-Smith S, Robertson JS, Vandijck M, Vanderstichele H, Barnham KJ, Ellis KA, Szoeke C, Macaulay L, Rowe CC, Villemagne VL, Ames D, Martins RN, Bush AI, Masters CL (2014) Changes in plasma amyloid beta in a longitudinal study of aging and Alzheimer's disease. Alzheimers Dement 10, 53-61.

[8] Doecke JD, Laws SM, Faux NG, Wilson W, Burnham SC, Lam CP, Mondal A, Bedo J, Bush AI, Brown B, De Ruyck K, Ellis KA, Fowler C, Gupta VB, Head R, Macaulay SL, Pertile K, Rowe CC, Rembach A, Rodrigues M, Rumble R, Szoeke C, Taddei K, Taddei T, Trounson B, Ames D, Masters CL, Martins RN; Alzheimer's Disease Neuroimaging Initiative; Australian Imaging Biomarker and Lifestyle Research Group (2012) Blood-based protein biomarkers for diagnosis of Alzheimer disease. Arch Neurol 69, 1318-1325.

[9] Burnham SC, Faux NG, Wilson W, Laws SM, Ames D, Bedo J, Bush AI, Doecke JD, Ellis KA, Head R, Jones G, Kiiveri H, Martins RN, Rembach A, Rowe CC, Salvado O, Macaulay SL, Masters CL, Villemagne VL (2014) A blood-based predictor for neocortical A[beta] burden in Alzheimer/'s disease: Results from the AIBL study. Mol Psychiatry 19, 519-526.

[10] Villemagne VL, Perez KA, Pike KE, Kok WM, Rowe CC, White AR, Bourgeat P, Salvado O, Bedo J, Hutton CA, Faux NG, Masters CL, Barnham KJ (2010) Blood borne amyloidbeta dimer correlates with clinical markers of Alzheimer's disease. J Neurosci 30, 6315-6322.

[11] Kiko T, Nakagawa K, Satoh A, Tsuduki T, Furukawa K, Arai H, Miyazawa T (2012) Amyloid beta levels in human red blood cells. PLoS One 7, e49620.

[12] Pesini P, Perez-Grijalba V, Monleon I, Boada M, Tarraga L, Martinez-Lage P, San-Jose I, Sarasa M (2012) Reliable measurements of the beta-amyloid pool in blood could help in the early diagnosis of AD. Int J Alzheimers Dis 2012, 604141.

[13] Qin W, Ho L, Wang J, Peskind E, Pasinetti GM (2009) S100A7, a novel Alzheimer's disease biomarker with non-amyloidogenic $\alpha$-secretase activity acts via selective promotion of ADAM-10. PLoS One 4, e4183.

[14] Simonsen AH, McGuire J, Podust VN, Davies H, Minthon L, Skoog I, Andreasen N, Wallin A, Waldemar G, Blennow K (2008) Identification of a novel panel of cerebrospinal fluid biomarkers for Alzheimer's disease. Neurobiol Aging 29, 961968.

[15] Watt AD, Perez KA, Faux NG, Pike KE, Rowe CC, Bourgeat P, Salvado O, Masters CL, Villemagne VL, Barnham KJ (2011) Increasing the predictive accuracy of amyloid-beta blood-borne biomarkers in Alzheimer's disease. J Alzheimers Dis 24, 47-59.

[16] Ellis KA, Bush AI, Darby D, De Fazio D, Foster J, Hudson P, Lautenschlager NT, Lenzo N, Martins RN, Maruff P, Masters C, Milner A, Pike K, Rowe C, Savage G, Szoeke C, Taddei K, Villemagne V, Woodward M, Ames D, null tARG (2009) The Australian Imaging, Biomarkers and Lifestyle (AIBL) study of aging: Methodology and baseline characteristics of 1112 individuals recruited for a longitudinal study of Alzheimer's disease. Int Psychogeriatr 21, 672-687.

[17] Rowe CC, Ng S, Ackermann U, Gong SJ, Pike K, Savage G, Cowie TF, Dickinson KL, Maruff P, Darby D, Smith C, Woodward M, Merory J, Tochon-Danguy H, O'Keefe G, Klunk WE, Mathis CA, Price JC, Masters CL, Villemagne VL (2007) Imaging beta-amyloid burden in aging and dementia. Neurology 68, 1718-1725.
[18] Benjamini Y, Hochberg Y (1995) Controlling the false discovery rate - A practical and powerful approach to multiple testing. J R Stat Soc Series B Stat Methodol 57, 289-300.

[19] Rembach A, Faux NG, Watt AD, Pertile KK, Rumble RL, Trounson BO, Fowler CJ, Roberts BR, Perez KA, Li QX, Laws SM, Taddei K, Rainey-Smith S, Robertson JS, Vandijck M, Vanderstichele H, Barnham KJ, Ellis KA, Szoeke C, Macaulay L, Rowe CC, Villemagne VL, Ames D, Martins RN, Bush AI, Masters CL (2014) Changes in plasma amyloid beta in a longitudinal study of aging and Alzheimer's disease. Alzheimers Dement 10, 53-61.

[20] Blennow K, Hampel H, Weiner M, Zetterberg H (2010) Cerebrospinal fluid and plasma biomarkers in Alzheimer disease. Nat Rev Neurol 6, 131-144.

[21] Humpel C (2011) Identifying and validating biomarkers for Alzheimer's disease. Trends Biotechnol 29, 26-32.

[22] Marksteiner J, Hinterhuber H, Humpel C (2007) Cerebrospinal fluid biomarkers for diagnosis of Alzheimer's disease: Beta-amyloid(1-42), tau, phospho-tau-181 and total protein. Drugs Today 43, 423-431.

[23] Randall C, Mosconi L, Leon M, Glodzik L (2013) Cerebrospinal fluid biomarkers of Alzheimers disease in cognitively healthy elderly. Front Biosci 18, 1150-1173.

[24] Peskind ER, Riekse R, Quinn JF, Kaye J, Clark CM, Farlow MR, Decarli C, Chabal C, Vavrek D, Raskind MA, Galasko D (2005) Safety and acceptability of the research lumbar puncture. Alzheimer Dis Assoc Disord 19, 220-225.

[25] Munro NP, Cairns DA, Clarke P, Rogers M, Stanley AJ, Barrett JH, Harnden P, Thompson D, Eardley I, Banks RE, Knowles MA (2006) Urinary biomarker profiling in transitional cell carcinoma. Int J Cancer 119, 2642-2650.

[26] Hancock RE, Diamond G (2000) The role of cationic antimicrobial peptides in innate host defences. Trends Microbiol $\mathbf{8}$, 402-410.

[27] Tao R, Jurevic RJ, Coulton KK, Tsutsui MT, Roberts MC, Kimball JR, Wells N, Berndt J, Dale BA (2005) Salivary antimicrobial peptide expression and dental caries experience in children. Antimicrob Agents Chemother 49, 3883-3888.

[28] Ganz T, Selsted ME, Szklarek D, Harwig SS, Daher K, Bainton DF, Lehrer RI (1985) Defensins. Natural peptide antibiotics of human neutrophils. J Clin Invest 76, 1427-1435.

[29] Selsted ME, Harwig SS, Ganz T, Schilling JW, Lehrer RI (1985) Primary structures of three human neutrophil defensins. J Clin Invest 76, 1436-1439.

[30] Daher KA, Lehrer RI, Ganz T, Kronenberg M (1988) Isolation and characterization of human defensin cDNA clones. Proc Natl Acad Sci U S A 85, 7327-7331.

[31] Cho Y-T, Su H, Huang T-L, Chen H-C, Wu W-J, Wu PC, Wu D-C, Shiea J (2013) Matrix-assisted laser desorption ionization/time-of-flight mass spectrometry for clinical diagnosis. Clin Chim Acta 415, 266-275.

[32] Kemik O, Kemik AS, Sumer A, Begenik H, Purisa S, Tuzun S (2013) Human neutrophil peptides 1, 2 and 3 (HNP 1-3): Elevated serum levels in colorectal cancer and novel marker of lymphatic and hepatic metastasis. Hum Exp Toxicol 32, 167-171.

[33] Melle C, Ernst G, Schimmel B, Bleul A, Thieme H, Kaufmann R, Mothes H, Settmacher U, Claussen U, Halbhuber KJ Von Eggeling F (2005) Discovery and identification of alphadefensins as low abundant, tumor-derived serum markers in colorectal cancer. Gastroenterology 129, 66-73.

[34] Mothes H, Melle C, Ernst G, Kaufmann R, von Eggeling F, Settmacher U (2008) Human Neutrophil Peptides 1-3-early markers in development of colorectal adenomas and carcinomas. Dis Markers 25, 123-129. 
[35] Craddock RM, Huang JT, Jackson E, Harris N, Torrey EF, Herberth M, Bahn S (2008) Increased alpha-defensins as a blood marker for schizophrenia susceptibility. Mol Cell Proteomics 7, 1204-1213.

[36] Zhang L, Yu W, He T, Yu J, Caffrey RE, Dalmasso EA, Fu S, Pham T, Mei J, Ho JJ, Zhang W, Lopez P, Ho DD (2002) Contribution of human $\alpha$-defensin 1,2, and 3 to the anti-HIV-1 activity of CD8 antiviral factor. Science 298, 995-1000.

[37] Hazrati E, Galen B, Lu W, Wang W, Ouyang Y, Keller MJ, Lehrer RI, Herold BC (2006) Human $\alpha$ - and $\beta$-defensins block multiple steps in herpes simplex virus infection. $J$ Immunol 177, 8658-8666.

[38] Krause DL, Muller N (2010) Neuroinflammation, microglia and implications for anti-inflammatory treatment in Alzheimer's disease. Int J Alzheimers Dis 2010, pii: 732806.

[39] Cras P, Kawai M, Siedlak S, Mulvihill P, Gambetti P, Lowery D, Gonzalez-DeWhitt P, Greenberg B, Perry G (1990) Neuronal and microglial involvement in beta-amyloid protein deposition in Alzheimer's disease. Am J Pathol 137, 241-246.

[40] Styren SD, Civin WH, Rogers J (1990) Molecular, cellular, and pathologic characterization of HLA-DR immunoreactivity in normal elderly and Alzheimer's disease brain. Exp Neurol 110, 93-104.

[41] Perlmutter LS, Barron E, Chui HC (1990) Morphologic association between microglia and senile plaque amyloid in Alzheimer's disease. Neurosci Lett 119, 32-36.

[42] Eikelenboom P, van Exel E, Hoozemans JJ, Veerhuis R, Rozemuller AJ, van Gool WA (2010) Neuroinflammation - an early event in both the history and pathogenesis of Alzheimer's disease. Neurodegener Dis 7, 38-41.

[43] Edison P, Archer HA, Gerhard A, Hinz R, Pavese N, Turkheimer FE, Hammers A, Tai YF, Fox N, Kennedy A, Rossor M, Brooks DJ (2008) Microglia, amyloid, and cognition in Alzheimer's disease: An [11C](R)PK11195-PET and [11C]PIB-PET study. Neurobiol Dis 32, 412-419.

[44] Koyama A, O’Brien J, Weuve J, Blacker D, Metti AL, Yaffe K (2013) The role of peripheral inflammatory markers in dementia and Alzheimer's disease: A meta-analysis. J Gerontol A Biol Sci Med Sci 68, 433-440.

[45] Bermejo P, Martin-Aragon S, Benedi J, Susin C, Felici E, Gil P, Ribera JM, Villar AM (2008) Differences of peripheral inflammatory markers between mild cognitive impairment and Alzheimer's disease. Immunol Lett 117, 198-202.

[46] Zhang J, Jia J, Qin W, Wang S (2013) Combination of plasma tumor necrosis factor receptors signaling proteins, betaamyloid and apolipoprotein E for the detection of Alzheimer's disease. Neurosci Lett 541, 99-104.

[47] O'Bryant SE, Xiao G, Barber R, Reisch J, Doody R, Fairchild T, Adams P, Waring S, Diaz-Arrastia R, for the Texas Alzheimer's Research Consortium (2010) A serum proteinbased algorithm for the detection of Alzheimer disease. Arch Neurol 67, 1077-1081.

[48] O'Bryant SE, Xiao G, Barber R, Reisch J, Hall J, Cullum CM, Doody R, Fairchild T, Adams P, Wilhelmsen K, DiazArrastia R (2011) A blood-based algorithm for the detection of Alzheimer's disease. Dement Geriatr Cogn Disord 32, 55-62. 